Sholikhah, et al/Jurnal Ekonomi Syariah Teori dan Terapan Vol. 6 No. 5 Mei 2019: 942-956; PERAN NILAI NILAI UKHUWAH DALAM PEMBERDAYAAN EKONOMI PETERNAK PADA PROGRAM TERNAK DESA BERDAYA NURUL HAYAT DI DESA SIDOMUKTI KECAMATAN KEPOH BARU KABUPATEN BOJONEGORO

\title{
PERAN NILAI - NILAI UKHUWAH PADA PROGRAM TERNAK DESA BERDAYA YAYASAN NURUL HAYAT SURABAYA DALAM PEMBERDAYAAN EKONOMI PETERNAK DI DESA SIDOMUKTI KECAMATAN KEPOH BARU KABUPATEN BOJONEGORO'
}

\author{
Imma Mufidatus Sholikhah \\ Departemen Ekonomi Syariah- Fakultas Ekonomi dan Bisnis-Universitas Airlangga \\ Email: imaaefendi@gmail.com \\ Irham Zaki \\ Departemen Ekonomi Syariah- Fakultas Ekonomi dan Bisnis-Universitas Airlangga \\ Email: irham-z@feb.unair.ac.id
}

\begin{abstract}
:
Nurul Hayat Foundation has several programs, one of which stands out is empowerment program empowered livestock village. In this program Nurul Hayat Foundation works with animal farmers who according to him are able to manage and give birth to healthy livestock. This research uses descriptive qualitative approach. The reason of the researcher using qualitative descriptive approach is to answer the questions that exist in the formulation of the problem comprehensively and deeply about how the role of ukhuwah in the village livestock program empower the Nurul Hayat Foundation Surabaya in empowerment of farmer's economy. The formulation of the problem was answered with data mostly obtained from interviews and observation. The source of data is the qurban animal farmers who cooperate with the Nurul Hayat Foundation Surabaya. The results showed that empowered livestock program at Yayasan Nurul Hayat had an impact on improving the welfare of farmers, this is not apart from applying ukhuwah value in program implementation. Networking, norms, reciprocal relationships and beliefs, the four points based on ukhuwah's value can have a positive impact on the success of the program.
\end{abstract}

Keywords: Empowerment, Ukhuwah Values, Zakah, Infaq, and Shadaqah, Nurul Hayat, LAZNAZ

\section{PENDAHULUAN}

\section{Latar Belakang}

Kemiskinan menjadi permasalahan yang cukup serius di Indonesia, sebagai negara berkembang, angka kemiskinan di Indonesia masih cukup tinggi. Kemiskinan menjadikan seseorang menjadi iri dengki terhadap orang-orang kaya. Maka dari itu, permasalahan kemiskinan harus segera ditindak-lanjuti. Pemerintah diharapkan mengambil langkah yang tepat dan cepat dalam menganggulangi masalah kemiskinan tersebut agar tidak menjadi permasalahan yang terus menerus berlarut-larut dalam negara ini.
Untuk melihat angka kemiskinan relatif di Indonesia, diharapkan Tabel 1 dapat membantu.

Tabel 1.

Jumlah dan Presentase Penduduk Miskin di Indonesia Tahun 2013-2017

\begin{tabular}{|c|c|c|c|c|}
\hline \multirow{2}{*}{ Periode } & \multicolumn{3}{|c|}{ Jumlah Penduduk Miskin (Juta Orang) } \\
\cline { 2 - 5 } & Maret & Perkotaan & Pedesaan & Total \\
\hline 2013 & September & 10,33 & 17,74 & 28,07 \\
\hline & Maret & 10,51 & 17,92 & 28,55 \\
\hline 2014 & Mept & 17,77 & 28,28 \\
\hline & September & 10,36 & 17,37 & 27,73 \\
\hline 2015 & Maret & 10,65 & 17,94 & 28,59 \\
\hline & September & 10,62 & 17,89 & 28,51 \\
\hline 2016 & Maret & 10,34 & 17,67 & 28,01 \\
\hline & September & 10,49 & 17,28 & 27,76 \\
\hline 2017 & Maret & 10,67 & 17,10 & 27,77 \\
\hline \multicolumn{4}{|c}{} \\
\hline
\end{tabular}

Berdasarkan data pada tabel 1 jumlah dan presentasi kondisi masyarakat miskin di Indonesia kemiskinan dipandang sebagai ketidakmampuan dari sisi ekonomi untuk memenuhi kebutuhan

\footnotetext{
${ }^{1}$ Jurnal ini merupakan bagian dari skripsi Imma Mufidatus Sholikhah, NIM: 041211431019 , yang diuji pada tanggal 18 Juli 2018.
} 
Sholikhah, et al/Jurnal Ekonomi Syariah Teori dan Terapan Vol. 6 No. 5 Mei 2019: 942-956; PERAN NILAI NILAI UKHUWAH DALAM PEMBERDAYAAN EKONOMI PETERNAK PADA PROGRAM TERNAK DESA BERDAYA NURUL HAYAT DI DESA SIDOMUKTI KECAMATAN KEPOH BARU KABUPATEN BOJONEGORO

dasar makanan dan bukan makanan.

Dari tabel di atas dapat diketahui jumlah penduduk miskin di Indonesia pada periode Maret 2013 sebesar 28,07 juta jiwa. Jika dibandingkan dengan data tahun selanjutnya di periode Maret 2014 mengalami kenaikan dalam tingkat kemiskinan, hal ini terbukti bahwa kondisi masyarakat di Indonesia sangat memprihatinkan (BPS,2018).

Selama periode Maret 2017September 2017, jumlah penduduk miskin di daerah perkotaan turun sebanyak 401,28 ribu orang (dari 10,67 juta orang pada Maret 2017 menjadi 10,27 juta orang pada September 2017), sementara di daerah perdesaan turun sebanyak 786,95 ribu orang (dari 17,10 juta orang pada Maret 2017 menjadi 16,31 juta orang pada September 2017). (BPS, 2018).

Dalam upaya pengentasan kemiskinan tidak hanya pemerintah yang ikut andil tetapi kontribusi masyarakat juga cukup besar. Dengan adanya zakat akan mampu membantu dalam hal penuntasan kemiskinan yang ada pada saat ini. Dan bukan hanya potensial dalam hal pengumpulan zakat saja melainkan harus ada perbaikan dalam hal pengelolaan zakat pada masa sekarang ini, dalam hal tersebut akan berpengaruh terhadap pendistribusian zakat jika pengelolaan zakat terbilang baik. Dalam hal pengelolaan harusnya ada dukungan dari beberapa kalangan baik dari pemerintah maupun masyarakat.
Kekuatan perintah menjalankan zakat sama kuatnya dengan perintah rukun Islam lainnya yaitu syahadat, sholat, puasa dan ibadah haji. Kewajiban dalam berzakat tercantum jelas dalam Al-Qur'an surat Al-Baqarah ayat 43 yang berbunyi :

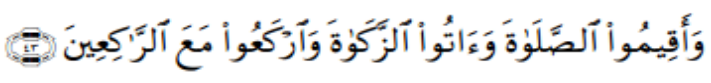

At' muruunannaasa bil birri wa tansauna anfusakum wa antum tatluunal kitaaba afalaa ta'qiluun(a)

43. dan dirikanlah sholat, tunaikanlah zakat dan ruku'lah bersama orang-orang yang ruku'

Salah satu lembaga amil zakat atau LAZ yang ada di Indonesia adalah Yayasan Nurul Hayat, lembaga ini memiliki tujuan yaitu mampu mengurangi kemiskinan dengan ZIS (Zakat, Infak, Sedekah). Lembaga yang berdiri sejak tahun 2001 dan berpusat di Surabaya ini memiliki beberapa kantor cabang diseluruh Indonesia. Selain itu lembaga ini juga bervisi menebar manfaat dan pemberdayaan di bidang dakwah, sosial, kesehatan dan ekonomi. Hal tersebut dibuktikan dengan adanya pemanfaatan dana zakat, infaq, sedekah yang masuk. Beberapa program yang dimiliki oleh Yayasan Nurul Hayat salah satunya yang menonjol adalah program pemberdayaan ternak desa berdaya. Dalam program ini Yayasan Nurul Hayat bekerjasama dengan para peternak hewan yang dikiranya mampu untuk mengelola dan melahirkan hewan ternak sehat. 
Sholikhah, et al/Jurnal Ekonomi Syariah Teori dan Terapan Vol. 6 No. 5 Mei 2019: 942-956; PERAN NILAI NILAI UKHUWAH DALAM PEMBERDAYAAN EKONOMI PETERNAK PADA PROGRAM TERNAK DESA BERDAYA NURUL HAYAT DI DESA SIDOMUKTI KECAMATAN KEPOH BARU KABUPATEN BOJONEGORO

Program tersebut bertujuan untuk menghidupkan potensi lokal masyarakat dan membangun kesejahteraan masyarakat. Hal ini sekaligus menginspirasi lahirnya pola pemberdayaan berbasis peternakan yang dapat mensejahterahkan. Selain mendapatkan keuntungan ekonomi para peternak ini juga mendapatkan pembinaan teknis beternak dan pembangunan etos kerja, semangat untuk mandiri dan pengalaman spiritual. Program riset dan pengembangan hewan ternak meliputi pembibitan, pakan, teknologi, dan manajemen.

Menurut Sanrego dan Taufia (2016:21) dalam islam, terkait dengan pemberdayaan umat Islam yang telah diajarkan oleh Rasulullah. Dengan modal sosial yang kuat, maka akan relatif mudah membangun komunitas dan hubungan timbal balik serta altruism yang baik pada masyarakat.

Dalam islam juga diajarkan mengenai semangat memberi dengan ikhlas. Namun dalam prakteknya masih ada beberapa yang jauh dari diidealkan oleh agama. Semisal di desa dengan penduduk yang miskin, inisiatif atau semangat untuk menolong masih sedikit. Pemberian bantuan hanya sekedar zakat konsumtif. Padahal, semangat untuk memberi ini tertuang beberapa kali dalam Al-Qur'an. Selain itu, tingkat kepercayan masyarakat sangat dipengaruhi dengan jaringan yang tercipta. Dapat dilihat pada surat Al-Hujurat: 10 seperti dibawah ini:
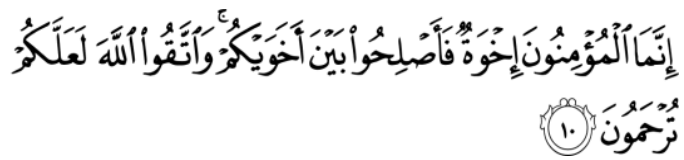

Innamā'l-mu'minūna ikhwatun fa-așlihū baina akhawaikum wattaqüllāha la állakum turhamūn.

"Orang-orang beriman itu sesungguhnya bersaudara. Sebab itu damaikanlah (perbaikilah hubungan) antara kedua saudaramu itu dan takutlah terhadap Allah, supaya kamu mendapat rahmat."

Maksud dari potongan ayat di atas adalah bahwa hakekat dari seorang mukmin adalah menjaga tali silaturahmi antar sesama saudara. Atau dalam Islam dapat disebut dengan istilah ukhuwah. Jika dikaitkan, ayat di atas menekankan pentingnya hubungan kepercayaan yang melandasi jaringan atau tali silaturahmi dan berlandaskan norma-norma yang dianut serta menghasilkan hubungan timbal balik yang saling bermanfaat.

Berbagai pandangan mengenai menjaga tali silahturahmi antar sesama saudara atau disebut juga dengan ukhuwah, muncul pertanyaan seperti: Bagaimana jika nilai-nilai ukhuwah ini tidak diterapkan dengan baik oleh masyarakat? Dampak apa yang akan terjadi? Salah satu contoh yang kurang baik adalah adanya tindak kriminalitas yang akhirnya membuat masyarakat menjadi kurang merasa aman saat berpergian. Kriminalitas seperti perampokan, begal, penipuan membuat kadar rasa aman seseorang menurun, yang artinya, tingkat kepercayaan seseorang juga ikut menurun. Selain itu, 
Sholikhah, et al/Jurnal Ekonomi Syariah Teori dan Terapan Vol. 6 No. 5 Mei 2019: 942-956; PERAN NILAI NILAI UKHUWAH DALAM PEMBERDAYAAN EKONOMI PETERNAK PADA PROGRAM TERNAK DESA BERDAYA NURUL HAYAT DI DESA SIDOMUKTI KECAMATAN KEPOH BARU KABUPATEN BOJONEGORO

tindak kejahatan seperti kasus korupsi juga turut menurunkan tingkat masyarakat pada birokrasi atau pemerintahan yang ada. Hasbullah dalam bukunya yang berjudul Social Capital: Menuju Keunggulan Budaya Manusia Indonesia menjelaskan bahwa trust adalah bentuk paling sederhana yang dapat tumbuh dan berkembang pada diri seseorang.

Munculnya berbagai pendapat mengenai nilai-nilai ukhuwah memunculkan pertanyaan, Bagaimana nilai-nilai ukhuwah pada suatu yayasan dapat meningkatkan kesejahteraan masyarakat? Unsur atau hal-hal apa saja yang perlu diperhatikan atau dilakukan agar suatu masyarakat ikut tergerak dalam program yang telah diagendakan dan atau dari kegiatan tersebut, terdapat peningkatan kesejahteraan pada individu yang turut serta pada komunitas. Karena, agar seorang individu tergerak hatinya untuk ikut ambil andil dalam suatu yayasan, diperlukan adanya rasa simpati yang dapat berupa rasa kagum, perhatian, peduli, empati, penghargaan, rasa tanggung jawab, atau kepercayaan pada seseorang (Robison dalam Syahra:2003).

\section{Rumusan Masalah}

Berdasarkan uraian latar belakang diatas, maka rumusan masalah yang dapat diajukan pada penelitian ini adalah, "Bagaimanakah peran nilai-nilai ukhuwah pada program ternak desa berdaya Yayasan Nurul Hayat Surabaya dalam pemberdayaan ekonomi peternak?"

\section{Tujuan Penelitian}

Tujuan utama yang ingin dicapai dalam penelitian ini adalah untuk mengetahui peran nilai-nilai ukhuwah pada program ternak desa berdaya Yayasan Nurul Hayat Surabaya dalam meningkatkan kesejahteraan masyarakat ekonomi peternak.

\section{LANDASAN PUSTAKA \\ Lembaga Amil Zakat}

Penghimpunan zakat merupakan tugas dari amil zakat, sebagaimana yang difirmankan Allah SWT dalam QS AtTaubah ayat103:

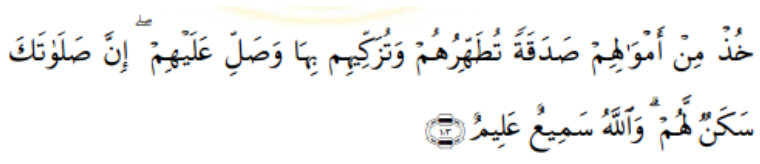

khudz min amwaalihim shadaqatan tuthahhiruhum watuzakkiihim bihaa washalli 'alayhim inna shalaataka sakanun lahum waallaahu samii'un 'aliimun

Ambillah zakat dari sebagian harta mereka, dengan zakat itu kamu membersihkan dan mensucikan mereka dan mendoalah untuk mereka. Sesungguhnya doa kamu itu (menjadi) ketenteraman jiwa bagi mereka. Dan Allah Maha Mendengar lagi Maha Mengetahui. (QS At-Taubah \{9\} : 103)

Merujuk pada ayat diatas, serta Undang-Undang Republik Indonesia nomor 23 tahun 2003 pasal 1 ayat (1) menyebutkan bahwa yang dimaksud dengan pengelolaan zakat adalah kegiatan perencanaan, pelaksanaan, dan pengoordinasian dalam 
Sholikhah, et al/Jurnal Ekonomi Syariah Teori dan Terapan Vol. 6 No. 5 Mei 2019: 942-956; PERAN NILAI NILAI UKHUWAH DALAM PEMBERDAYAAN EKONOMI PETERNAK PADA PROGRAM TERNAK DESA BERDAYA NURUL HAYAT DI DESA SIDOMUKTI KECAMATAN KEPOH BARU KABUPATEN BOJONEGORO

pengumpulan, pendistribusian, dan pendayagunaan zakat infaq dan shadaqah(ZIS).

Dilihat dari penjelasan diatas, maka akan akan ditemukan hal serupa pada Lembaga Amil Zakat yaitu sekelompok orang yang bersama - sama bekerjasama melaksanakan kegiatan dan aktivitas untuk mencapai tujuan utama mereka yaitu untuk mengelola zakat infaq dan shadaqah. Keberadaan

Lembaga Amil Zakat (LAZ) telah diatur menurut undang - undang nomor 38 tahun 1999 dan undang - undang nomor 23 tahun 2011 tentang Pengelolaan Zakat Bab II pasal 5 dan pasal 17 menyatakan bahwa lembaga amil zakat di Indonesia ada dua macam yaitu, Badan Amil zakat Nasional (BAZNAS) dan LAZ.

\section{Definisi Ukhuwah}

Ukhuwah yang biasa diartikan sebagai "persaudaraan" terambil dari akar kata yang pada mulanya berarti "memperhatikan". Makna asal ini memberi kesan bahwa persaudaraan mengharuskan adanya perhatian semua pihak yang merasa bersaudara. Boleh jadi, perhatian itu pada mulanya lahir karena adanya persamaan diantara pihak-pihak yang bersaudara, sehingga makna tersebut kemudian berkembang, dan pada akhirnya ukhuwah diartikan sebagai "setiap persamaan dan keserasian dari pihak lain, baik persamaan, keturunan, dari segi ibu, bapak atau keduanya maupun dari segi persusuan (Shihab, 1996:477-478).
Beberapa definisi dari ukhuwah yang dikemukakan oleh para ahli, antara lain sebagai berikut:

"Secara bahasa kata ukhuwah berarti persaudaraan. Kata ini seakar dengan kata yang berarti memperhatikan. Ini mengisyaratkan, agar terwujud persaudaraan, perlu ada perhatian antara mereka yang bersaudara. Perhatian muncul karena ada persamaan diantara mereka. Dari sini kata ukhuwah dimaknai sebagai persamaan dan keserasian dengan pihak lain, meliputi persamaan keturunan, persusuan, suku, bangsa, agama, dan profesi " (Firdaus, 2006:163).

\section{Macam - Macam Ukhuwah}

Menurut Shihab (1996:480-481)

kitab suci Al-Qur'an memperkenalkan paling tidak empat macam persaudaraan, yaitu:

1. Ukhuwah 'ubudiyyah

2. Ukhuwah insaniyyah (basyariyyah)

3. Ukhuwah wathaniyyah wa an-nasab

4. Ukhuwwah fi din Al-Islam

Ukhuwah yang secara jelas dinyatakan oleh Al-Qur'an adalah persaudaraan seagama Islam, dan persaudaraan yang jalinannya bukan karena agama. Ini tercermin dengan jelas dari pengamatan terhadap penggunaan bentuk jamak kata tersebut dalam AlQur'an, yang menunjukkan dua arti kata akh' yaitu: Pertama, ikhwan, yang biasanya digunakan untuk persaudaraan tidak sekandung. Kata ini ditemukan sebanyak 22 kali sebagian disertakan 
Sholikhah, et al/Jurnal Ekonomi Syariah Teori dan Terapan Vol. 6 No. 5 Mei 2019: 942-956; PERAN NILAI NILAI UKHUWAH DALAM PEMBERDAYAAN EKONOMI PETERNAK PADA PROGRAM TERNAK DESA BERDAYA NURUL HAYAT DI DESA SIDOMUKTI KECAMATAN KEPOH BARU KABUPATEN BOJONEGORO

dengan kata ad-din (agama) seperti dalam surat At Taubah : 11 yaitu :

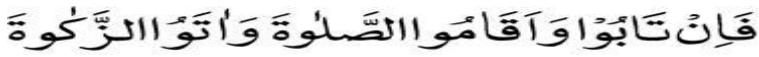

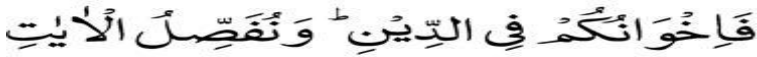

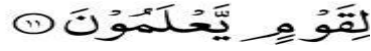

fa-in taabuu wa-aqaamuv alshshalaata waaatawuu alzzakaata fa-ikhwaanukum fii alddiini wanufashshilu al-aayaati liqawmin ya'lamuuna

"Apabila mereka bertobat, melaksanakan shalat, dan menunaikan zakat, mereka adalah saudara-saudara kamu seagama." (Q.S. Taubah:11).

Sedangkan sebagian lain tidak dirangkaikan dengan kata ad-din (agama) seperti surat Al Baqarah : 220 yaitu

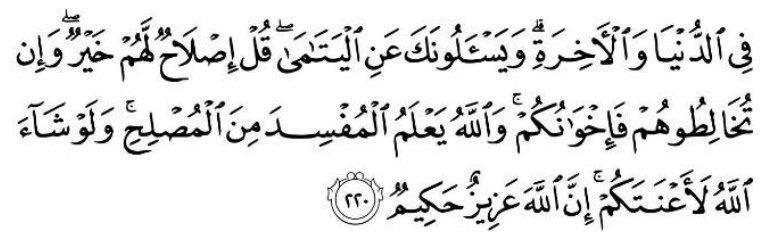

fii alddunyaa waal-aakhirati wayasaluunaka 'ani alyataamaa qul ishlaahun lahum khayrun wa-in tukhaalithuuhum faikhwaanukum waallaahu ya'lamu almufsida mina almushlihi walaw syaa-a allaahu la-a'natakum inna allaaha 'aziizun hakiimun

"Tentang dunia dan akhirat. dan mereka bertanya kepadamu tentang anak yatim, katakalah: "Mengurus urusan mereka secara patut adalah baik, dan jika kamu bergaul dengan mereka, Maka mereka adalah saudaramu; dan Allah mengetahui siapa yang membuat kerusakan dari yang Mengadakan perbaikan. dan Jikalau Allah menghendaki, niscaya Dia dapat mendatangkan kesulitan kepadamu. Sesungguhnya Allah Maha Perkasa lagi Maha Bijaksana" (Q.S. Al-Baqarah:220).

Ayat-ayat tersebut secara tegas dan nyata menunjukkan bahwa $\mathrm{Al}$ Qur'an memperkenalkan persaudaraan seagama dan persaudaraan tidak seagama (Shihab, 1996:481-482).

\section{Ukhuwah dalam Ekonomi}

Ada banyak dalil yang menerangkan tentang ukhuwah namun hal tersebut tidaklah ada apa-apanya jika hanya mengetahui saja dan tidak mengamalkannya. Salah satu dalil dalam Al-Qur'an yang menjadi landasan pengamalan konsep ukhuwah yaitu surah Al-Hujurat ayat 10 :

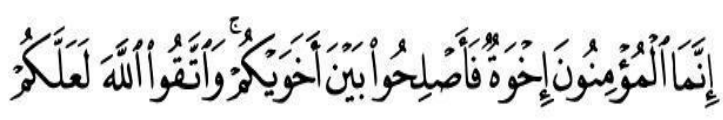

innamaa Imu'minuuna ikhwatun faashlihuu bayna akhawaykum wattaque laaha la'allakum turhamuun

Artinya :

"Orang-orang beriman itu Sesungguhnya bersaudara. sebab itu damaikanlah (perbaikilah hubungan) antara kedua saudaramu itu dan takutlah terhadap Allah, supaya kamu mendapat rahmat".

Berdasarkan ayat di atas Shihab (1996:490-491) berpendapat bahwa puluhan ayat berbicara tentang kewajiban melakukan shalah atau ishlah. Dalam kamus-kamus bahasa Arab, kata shalah diartikan sebagai antonim dari 
Sholikhah, et al/Jurnal Ekonomi Syariah Teori dan Terapan Vol. 6 No. 5 Mei 2019: 942-956; PERAN NILAI NILAI UKHUWAH DALAM PEMBERDAYAAN EKONOMI PETERNAK PADA PROGRAM TERNAK DESA BERDAYA NURUL HAYAT DI DESA SIDOMUKTI KECAMATAN KEPOH BARU KABUPATEN BOJONEGORO

kata fasad (kerusakan), yang juga dapat diartikan sebagai yang bermanfaat.

Dalam menjalankan sebuah program ekonomi sosial diperlukan perencanaan yang matang seperti halnya dalam menjalankan sebuah bisnis, diperlukan model bisnis sebagai sebuah logika keseluruhan bisnis yang diberlakukan dalam hubunganya dengan pelanggan, rantai nilai yang dipunyai, sumber daya, manajemen operasional, hingga desain pendapatan atau keuntungan dan keberlangsungan entitas bisnis. (Fauroni, 2016:3)

Dalam penelitian ini, penulis memakai nilai - nilai ukhuwah dan nilai nilai dalam menjalankan kegiatan ekonomi dengan kata lain nilai - nilai ukhuwah sebagai landasan dasar dalam sebuah pondasi kegiatan ekonomi.

Fauroni (2016:4) mengatakan bahwa dalam sebuah kegiatan ekonomi diperlukan empat pilar utama yaitu network, operation, value proposition, dan trust. Keempat pilar tersebut sejalan dengan nilai - nilai ukhuwah yang digunakan oleh penulis yaitu silahturahmi, universal, tarahum, ta'awun, keadilan, daya saing, amanah, huznuzhan.

\section{Ukhuwah sebagai Episentrum}

Di masyarakat, ukhuwah bukan hanya terlihat dalam ritme kehidupan sosial, namun berlaku dan mentradisi dalam relasi ekonomi dan bisnis. Menurut Fauroni (2016:7) Episentrum ukhuwah berkonsekuensi pula terhadap ekspresi budaya kolektif, ke dalam dan ke luar.
Fauroni menemukan sebuah konstruksi model bisnis berbasis ukhuwah yang dapat digambarkan sebagai berikut:

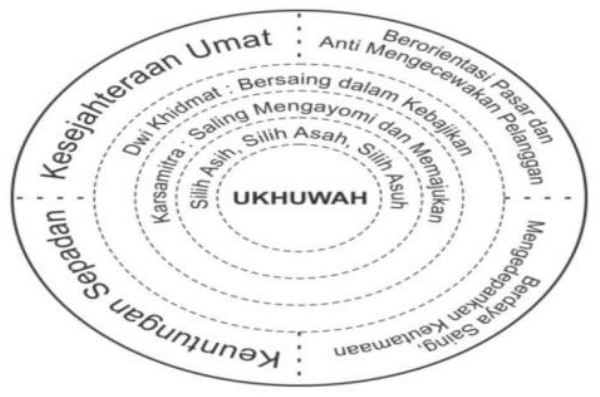

Gambar 1.

konstruksi model bisnis berbasis ukhuwah Pada gambar tersebut, Fauroni menjelaskan bahwa episentrum ukhuwah terekspresi menjadi mata rantai nilai meliputi tiga silih, yaitu silih asih silih asuh dan silih asah, saling mengayomi dan memajukan dalam kerjasama kemitraan yang kuat serta komitmen dwi khidmat. Dwi khidmat adalah komitmen masyarakat dalam kebajikan sebagai implementasi pengabdian kepada umat dan pesantren guna peningkatan kesejahteraan.

Paduan sikap dan kesadaran itu kemudian terekspresi ke luar menjadi budaya bisnis atau model bisnis berbasis ukhuwah yang ditopang empat elemen pokok. Keempat elemen itu meliputi, pertama, berorientasi pasar dan menghindarkan dari mengecewakan pelanggan. Kedua, kesadaran berdaya saing, mengedepankan keutamaan dalam keseluruhan proses bisnis. Ketiga, keuntungan yang sepadan antara material dan spiritual dan keempat, berdampak langsung pada peningkatan 
Sholikhah, et al/Jurnal Ekonomi Syariah Teori dan Terapan Vol. 6 No. 5 Mei 2019: 942-956; PERAN NILAI NILAI UKHUWAH DALAM PEMBERDAYAAN EKONOMI PETERNAK PADA PROGRAM TERNAK DESA BERDAYA NURUL HAYAT DI DESA SIDOMUKTI KECAMATAN KEPOH BARU KABUPATEN BOJONEGORO

kesejahteraan dan keadilan sosial ekonomi umat.

\section{Indikator Nilai-Nilai Ukhuwah}

Dalam penelitian ini Indikator dalam menilai nilai - nilai ukhuwah dalam penelitian ini akan dijelaskan pada tabel berikut:

Tabel 2.

Tabel Indikator Nilai - Nilai Ukhuwah

\begin{tabular}{|c|c|c|c|}
\hline No. & Variabel & Pengertian & Indikator \\
\hline 1. & silahturahim & $\begin{array}{l}\text { Menjalin sebuah hubungan } \\
\text { baik antar sesama umat } \\
\text { manusia }\end{array}$ & $\begin{array}{l}\text { a) Dalam setiap kegiatan } \\
\text { mampu menjalin atau } \\
\text { menciptakan hubungan } \\
\text { baik terhadap orang lain. } \\
\text { b) Mampu menjaga hubungan } \\
\text { baik yang telah terbangun } \\
\text { sebelumnya. }\end{array}$ \\
\hline 2. & Universal & $\begin{array}{l}\text { Mencakup secara seluruh, } \\
\text { untuk umat manusia tanpa } \\
\text { membedakannya dari ras, } \\
\text { suku, agama, maupun } \\
\text { lainnya. }\end{array}$ & $\begin{array}{l}\text { a) Tidak membedakan } \\
\text { muslim maupun non- } \\
\text { muslim. } \\
\text { b) Tidak membedakan berasal } \\
\text { dari suku, ras, atau } \\
\text { golongan tertentu. }\end{array}$ \\
\hline 3. & Daya Saing & $\begin{array}{l}\text { Kemampuan beradaptasi } \\
\text { dan berinovasi guna } \\
\text { menjaga kemampuan } \\
\text { untuk bersaing dan } \\
\text { berkembang }\end{array}$ & $\begin{array}{l}\text { a) Kemampuan untuk } \\
\text { menjaga kualitas yang } \\
\text { dimiliki. } \\
\text { b) Inovasi dan ide yang } \\
\text { dimiliki untuk memberikan } \\
\text { sebuah pengembangan dan } \\
\text { kemajuan }\end{array}$ \\
\hline 4. & Keadilan & $\begin{array}{l}\text { Memberikan suatu hal } \\
\text { secara yang telah menjadi } \\
\text { hak maupun kewajibannya } \\
\text { sesuai dengan ketentuan } \\
\text { yang berlaku dan tidak } \\
\text { menimbulkan kerugian } \\
\text { dalam salah satu pihak }\end{array}$ & $\begin{array}{l}\text { a) Dalam menjalankan } \\
\text { kegiatannya harus sesuai } \\
\text { dengan syariat dan aturan } \\
\text { yang berlaku. } \\
\text { b) Dalam menjalankan } \\
\text { kegiatannya tidak ada salah } \\
\text { satu pihak yang merasa } \\
\text { dirugikan. }\end{array}$ \\
\hline
\end{tabular}

\begin{tabular}{|c|c|c|c|}
\hline 5. & Tarahum & $\begin{array}{lr}\text { Upaya untuk saling } \\
\text { mengasihi } \\
\text { memberikan manfaat }\end{array}$ & $\begin{array}{lr}\text { a) Dalam } & \text { menjalankan } \\
\text { kegiatannya } & \text { mampu } \\
\text { memberikan manfaat } & \text { mada } \\
\text { kepada sekitar baik kepada } \\
\text { ummat maupun } \\
\text { lingkungan. } \\
\text { b) Memilik rasa kepedulian } \\
\text { terhadap sesama } \\
\end{array}$ \\
\hline 6. & Ta'awun & $\begin{array}{l}\text { Upaya untuk saling tolong } \\
\text { menolong dalam hal } \\
\text { kebaikan guna mencapai } \\
\text { kemaslahatan umat }\end{array}$ & $\begin{array}{l}\text { a) Memberikan upaya } \\
\text { pertolongan pada orang } \\
\text { lain yang membutuhkan } \\
\text { bantuan. } \\
\text { b) Memliki rasa kepekaan } \\
\text { terhadap situasi dan } \\
\text { kondisi yang terjadi } \\
\text { disekitar sehingga mampu } \\
\text { memberikan pertolongan } \\
\text { dalam saat yang tepat. }\end{array}$ \\
\hline 7. & Amanah & $\begin{array}{ll}\text { Dapat dipercaya } & \text { dalam } \\
\text { menjalankan } & \text { sebuah } \\
\text { titipan atau suatu hal yg } \\
\text { dipercayakan }\end{array}$ & $\begin{array}{l}\text { a) Memberikan jaminan rasa } \\
\text { aman kepada orang lain } \\
\text { dalam menjalin sebuah } \\
\text { hubungan. } \\
\text { b) Mampu menjalankan } \\
\text { kewajiban seusai dengan } \\
\text { aturan maupun syariat yang } \\
\text { berlaku. }\end{array}$ \\
\hline 8. & Huznuzhan & $\begin{array}{l}\text { Berbaik sangka dalam } \\
\text { memandang }\end{array}$ & $\begin{array}{l}\text { a) Tidak berpikiran buruk dan } \\
\text { mampu berpikir positif } \\
\text { terhadap suatu kondisi } \\
\text { yang tengah terjadi. } \\
\text { b) Mampu berpikir positif } \\
\text { terhadap orang lain }\end{array}$ \\
\hline
\end{tabular}

Definisi dan Tujuan Pemberdayaan

Hadi dalam Rappaport (2004:3)

menjelaskan bahwa pemberdayaan adalah suatu cara dimana rakyat, organisasi, dan komunitas diarahkan agar mampu menguasai (atau berkuasa atas) kehidupannya.

Pengertian pemberdayaan menurut Hikmat dalam Ardle (2010:14) pemberdayaan sebagai proses pengambilan keputusan oleh orang-orang yang secara konsekuen melaksanakan keputusan tersebut.

Tujuan dari pemberdayaan menunjuk pada keadaan atau hasil yang ingin dicapai oleh sebuah perubahan sosial yaitu masyarakat yang berdaya, memiliki kekuasaan atau pengetahuan dan kemampuan fisik, ekonomi, maupun sosial seperti memiliki kepercayaan diri, mampu menyampaikan aspirasi, mempunyai mata pencaharian, berpartisipasi dalam kegiatan sosial dan mandiri dalam melaksanakan tuanya pemberdayaan masyarakat merupakan tuntutan utama pembangunan, ini terkait dengan teori sumber daya manusia yang memandang mutu penduduk sebagai kunci utama pembangunan.

Human capital teory, menjelaskan: bahwa manusia merupakan sumber daya utama, berperan sebagai subjek baik dalam upaya peningkatan taraf hidup dirinya, maupun dalam melestarikan dan memanfaatkan lingkungannya. Menurut teori ini, konsep-konsep pendidikan harus didasarkan pada anggapan bahwa modal yang dimiliki manusia itu terdapat pada dirinya sendiri, berupa sikap, pengetahuan, ketrampilan, dan aspirasi.

Konsep Pemberdayaan (Tamkin) dalam Prespektif Al-Qur'an 
Sholikhah, et al/Jurnal Ekonomi Syariah Teori dan Terapan Vol. 6 No. 5 Mei 2019: 942-956; PERAN NILAI NILAI UKHUWAH DALAM PEMBERDAYAAN EKONOMI PETERNAK PADA PROGRAM TERNAK DESA BERDAYA NURUL HAYAT DI DESA SIDOMUKTI KECAMATAN KEPOH BARU KABUPATEN BOJONEGORO

Definisi tamkin dengan pemberdayaan disebutkan oleh Raihan Muhammad Raihan dalam Sanrego dan Taufik (2016:77): "Pemberdayaan yang berkelanjutan (at-tamkin al-mustadam) maksudnya adalah memebrikan kekuasaan penuh kepada masyarakat agar dirinya berkembang dan bisa mencapai pengembangan tersebut dan memahami dari segala sisi".

Pengertian tersebut dalam bahasa ekonomi bisa diistilahkan dengan pemberdayaan, dimana gambaran tentang pemberdayaan tidak lepas dari kekuasaan individu atau kelompok yang memiliki kesempatan untuk meraih kekuasaan dari kaum berpunya kepada kaum yang tidak berpunya. Pemberdayaan bertujuan untuk meningkatkan keberdayaan mereka yang telah dirugikan.

\section{Indikator Keberhasilan Pemberdayaan}

Terkait dengan kriteria keberhasilan yang digunakan untuk suatu proses evaluasi, Feurstein (1990) dalam Adi (2008) mengajukan beberapa indikator yang perlu dipertimbangkan. Indikator dibawah ini adalah Sembilan indikator yang paling sering digunakan untuk mengevaluasi keberhasilan suatu kegiatan pemberdayaan yaitu:

a) Indikator Ketersediaan

b) Indikator Relevansi

c) Indikator Keterjangkauan

d) Indikator Pemanfaatan

e) Indikator Cakupan

f) Indiktor Kualitas g) Indikator Upaya

h) Indikator Efesiensi

i) Indikator Dampak

Adapun tujuan kegiatan dalam jangka panjangnya adalah kemandirian yaitu pengembangan kapasitas dan pengitegrasian masyarakat yang dititikberatkan pada tujuan proses. Sedangkan dalam penelitian ini menggunakan beberapa indikator guna mencapai hasil dari penelitian ini, yaitu indikator pemanfaatan, efisiensi, dampak, serta transformasi mustahiq.

\section{METODE PENELITIAN}

\section{Pendekatan Penelitian}

Penelitian ini menggunakan pendekatan kualitatif deskriptif. Menurut Yin (2009:2) pendekatan kualitatif adalah pendekatan dengan menggunakan data yang berupa kalimat tertulis atau lisan, peristiwa-peristiwa, pengetahuan atau proyek studi yang bersifat deskriptif. Pendekatan kualitatif dengan metode deskriptif adalah mengkomunikasikan realitas yang ada dengan berdasarkan sudut pandang dari informan.

Alasan peneliti menggunakan pendekatan kualitatif deskriptif adalah untuk menjawab pertanyaan yang ada pada rumusan masalah secara komprehensif dan mendalam mengenai bagaimana peran-peran nilai ukhuwah pada program ternak desa berdaya yayasan Nurul Hayat Surabaya dalam pemberdayaan ekonomi peternak. Rumusan masalah dijawab dengan data yang sebagian besar diperoleh dari 
wawancara dan observasi. Sumber data adalah para peternak hewan qurban yang melakukan kerjasama dengan yayasan Nurul Hayat Surabaya.

\section{Jenis Dan Sumber Data}

Berdasarkan sumbernya terdapat dua jenis sumber data yang dapat dikumpulkan oleh peneliti, yaitu:

1. Data primer, yaitu data yang diperoleh peneliti secara langsung dari informan melalui wawancara dan observasi yang didapatkan dari Key Informan yang berkaitan dengan permasalahan yang sedang diteliti.

2. Data sekunder yaitu data yang berunsur non-manusia sebagai data pendukung penelitian, data yang dimaksud adalah data yang bersifat dokumen, seperti arsip, rekaman, foto, jurnal, maupun artikel yang berkaitan dengan topic penelitian.

\section{Populasi dan Sampel}

Informan yang diambil dalam penelitian ini adalah peternak hewan yang melakukan kerjasama dengan yayasan Nurul Hayat Surabaya pada program pemberdayaan ekonomi peternak yang telah dianggap representatif untuk memberikan hasil yang menunjang penelitian. Kriteria informan dalam penelitian ini adalah sebagai berikut:

a. Peternak hewan yang melakukan kerjasama dengan Yayasan Nurul Hayat Surabaya pada program ternak desa berdaya yang masih aktif menjalankan kerjasama tersebut. b. Peternak hewan harus menguasai dan memahami tentang bagaimana mekanisme kerjasama dalam pemberdayaan ekonomi peternak.

c. Perangkat desa sebagai pengelola data mengenai peternak hewan.

\section{HASIL PENELITIAN DAN PEMBAHASAN}

\section{Nilai-Nilai Ukhuwah Yang Muncul}

Keempat aspek utama memiliki bagian indikator sendiri yang bertujuan untuk mempermudah proses kerja pemberdayaan itu sendiri. Aspek network di dalamnya mengandung poin slihaturahmi dan universal, aspek operation memliki daya saing dan keadilan, aspek value proposition terdapat tarahum dan ta'awun, sedangkan trust di dalamnya terdapat dan huznuzan.

\section{Aspek Jaringan}

Tabel 3.

Aspek Jaringan

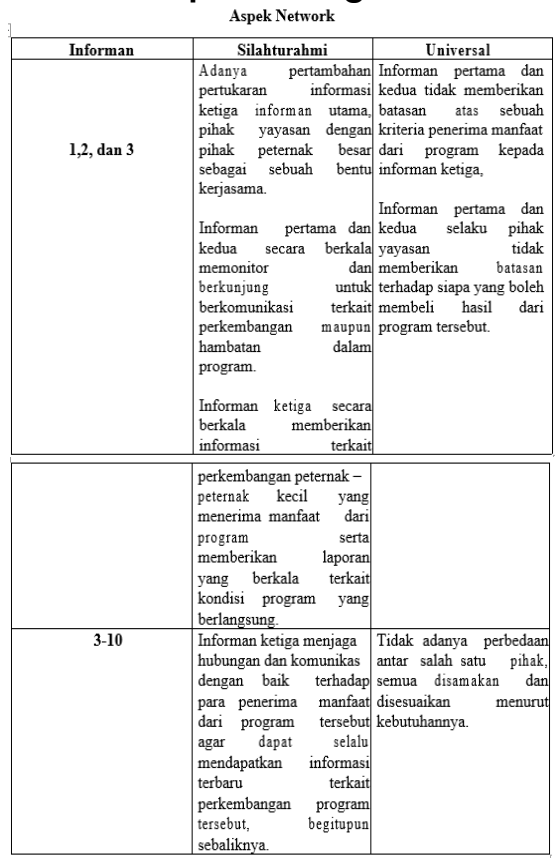

\section{Norma}


Tabel 4.

Aspek Operasi

Aspek Operation

\begin{tabular}{|c|c|c|}
\hline Informan & Daya Saing & Keadilan \\
\hline 1- 10 & 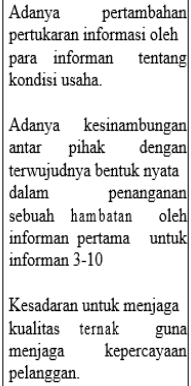 & $\begin{array}{l}\text { Keberhasilan menjaga } \\
\text { hak dan kewaiban } \quad \text { yang } \\
\text { telah disepakati bersama } \\
\text { sebelumnya } \\
\text { Tidak adanya } \\
\text { yang kerugian } \\
\text { ataupun dirasakan bulkan } \\
\text { salah satu informan. }\end{array}$ \\
\hline
\end{tabular}

\section{Hubungan Timbal Balik}

Tabel 5.

Aspek Value Proposition

\begin{tabular}{|c|c|c|}
\hline Informan & Tarahum & Ta'awun \\
\hline $1-10$ & $\begin{array}{l}\text { Telah muncul hubungan timbal balik } \\
\text { yang sangat menguntungkan dimana } \\
\text { pihak peternak mendapatkan bantuan } \\
\text { dana serta pelatihan yang dapat } \\
\text { menunjang usaha ternak mereka dan } \\
\text { bertambhanya pertemanan yang } \\
\text { dialami oleh informan. }\end{array}$ & $\begin{array}{l}\text { Para informan saling } \\
\text { tolong menolong dalam } \\
\text { prakteknya. } \\
\text { Informan pertama dan } \\
\text { kedua memberikan } \\
\text { pertolongan pada pihak } \\
\text { Peternak dalam } \\
\text { mengatasi hambatan yang } \\
\text { muncul dalam program } \\
\text { tersebut secara nyata }\end{array}$ \\
\hline
\end{tabular}

4. Aspek Kepercayaan

Tabel 6.

Aspek Trust Informant Aspek Trust Informan

\begin{tabular}{|c|c|c|}
\hline \multicolumn{3}{|c|}{ Aspek Trust Info } \\
\hline Informan & Amanah & Huznuzhan \\
\hline $1-10$ & $\begin{array}{l}\text { Informan ketiga sampai sepuluh telah } \\
\text { memberikan bukti bahwa mereka dapat } \\
\text { menjaga kepercayaan yang telah } \\
\text { diberikan kepada mereka. } \\
\text { Informan ketiga sampai sepuluh juga } \\
\text { senantiasa memberikan laporan serta } \\
\text { informasi terkini terkait aktivitas } \\
\text { program tersebut } \\
\text { Informan pertama dan kedua juga telah } \\
\text { membuktikan bahwa mereka dapat } \\
\text { dipercaya dengan tidak meninggalkan } \\
\text { para peternak bekerja sendiri tanpa } \\
\text { adanya dukungan dari mereka }\end{array}$ & 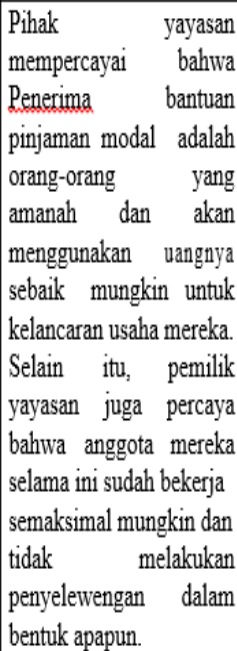 \\
\hline
\end{tabular}

Sumber: Diolah oleh penulis

\section{Model Pemberdayaan}

Ternak Desa Berdaya ini merupakan program yang ada pada setiap tahun. Hasil dari program ini yaitu kambing-kambing yang sehat dan bugar. Program Ternak Desa Berdaya merupakan program pemberdayaan untuk peternak dengan konsep peternakan modern. Selain itu pemberian makan untuk kambing sudah menggunakan fermentasi pakan.

Dalam program ini pihak peternak dan Yayasan Nurul Hayat selalu mengontrol perkembangan hewan ternaknya. Kambing-kambing yang dirasa sudah siap untuk dipasarkan pada saat Idul Adha akan ditimbang dan dicek terlebih dahulu untuk mengetahui apakah layak untuk dipasarkan. Meski demikian tidak menutup kemungkinan bahwa apabila dipasarkan di pasar selain momen Idul Adha. Untuk lebih memahaminya diharapkan gambar berikut dapat membantu.

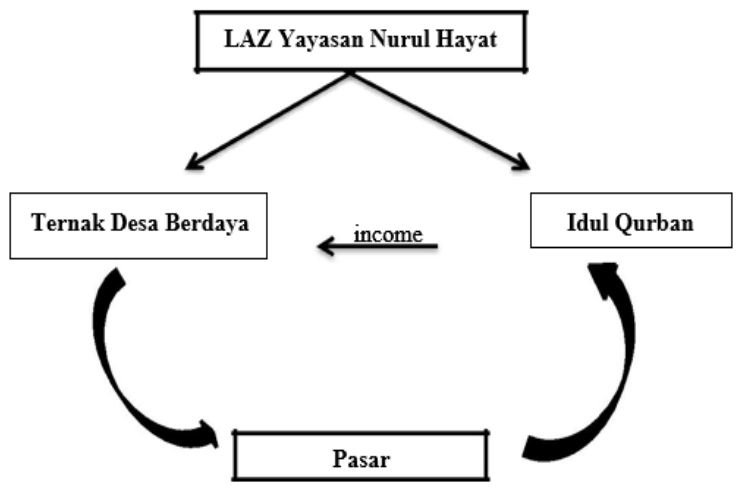

Gambar 2.

\section{Putaran Program Ternak Desa Berdaya}

Pada gambar tersebut diketahui bahwa LAZ Yayasan Nurul Hayat memiliki program Ternak Desa Berdaya. Selain 
Sholikhah, et al/Jurnal Ekonomi Syariah Teori dan Terapan Vol. 6 No. 5 Mei 2019: 942-956; PERAN NILAI NILAI UKHUWAH DALAM PEMBERDAYAAN EKONOMI PETERNAK PADA PROGRAM TERNAK DESA BERDAYA NURUL HAYAT DI DESA SIDOMUKTI KECAMATAN KEPOH BARU KABUPATEN BOJONEGORO

diberi oleh LAZ Yayasan Nurul Hayat, kambing-kambing tersebut juga dijual di pasar di luar hari raya Idul Adha. Hal tersebut sangat menguntungkan LAZ Yayasan Nurul Hayat, karena LAZ Yayasan Nurul Hayat tidak lagi susah-susah mencari tengkulak kambing yang bagus dan sehat untuk memenuhi kebutuhan qurban.

Secara teknis program pemberdayaan Ternak Desa Berdaya tersebut dijelaskan berikut ini : Peternak membeli bibit kambing rata-rata berkisar seharga Rp800000 yang akan dipelihara sekitar 3-4 bulan atau 120 hari. Apabila sudah memenuhi syarat penjualan, yang dilihat dari berat kambing dan kesehatan kambing, maka kambing tersebut layak untuk dijual. Sudah dijelaskan sebelumnya ketika momen hari Raya Idul Adha, kambing dibeli oleh Nurul Hayat. Ketika bukan momen hari Raya Idul Adha maka kambing di jual di pasar.

Hasil penjualan kambing tersebut dihitung keuntungannya. Keuntungan yang diterima para peternak berbedabeda tergantung beratnya kambing yang dipelihara, karena beratnya kambing mempengaruhi harga kambing. Semakin berat kambingnya semakin mahal harga jualnya, maka semakin banyak pula keuntungan yang didapatkannya.

\section{Analisis Keberhasilan Program Pemberdayaan Ternak Desa Berdaya}

Berikut analisis keberhasilan program Ternak Desa Berdaya oleh LAZ Yayasan Nurul Hayat yang diukur melalui lima indikator, yaitu kesejahteraan yang terdiri dari kebutuhan pangan, sandang dan papan, serta aspek spiritual, bekerja, ketidaktergantungan, penghasilan, dan transformasi mustahik menjadi muzaki.

\section{Kesejahteraan}

Indikator kesejahteraan dibagi menjadi empat hal, yaitu sandang, pangan, papan, dan aspek spiritual. Hasil dari empat hal tersebut dijelaskan sebagai berikut:

1. Pangan

Pangan merupakan kebutuhan dasar setiap individu. Semua informan menuturkan kebutuhan pangannya mengalami kondisi yang lebih baik setelah mengikuti program Ternak Desa Berdaya.

2. Sandang

Bahwa sebelum dan sesudah mengikuti program, kebutuhan sandang para informan telah terpenuhi, kecuali informan ketiga dan kelima. Informan ketiga dan kelima menjelaskan bahwa tambahan pendapatan yang didapat dari program ini digunakan untuk membayar sekolah anak dan untuk membayar cicilan motor.

3. Papan

Pada penelitian ini semua informan menuturkan telah tinggal ditempat yang layak, meskipun dua diantara empat informan masih belum memiliki tempat tinggalyang artinya masih tinggal bersama orang tua. Meskipun demikian para informan telah tinggal dirumah yang layak 
huni. Sehingga kebutuhan papan mereka terpenuhi.

4. Aspek Spiritual

Pada aspek spiritual mengalami peningkatan, dikarenakan adanya program khusus keagamaan untuk peternak. Diadakannya kajian dakwah setiap bulan untuk melatih dan memberikan manfaat betapa pentingnya menyeimbangkan antara kehidupan dunia dan kehidupan akhirat.

\section{Penghasilan}

Peningkatan penghasilan merupakan salah satu faktor yang penting untuk mengukur berhasil atau tidaknya suatu program. Tabel berikut menunjukkan peningkatan penghasilan para informan selama mengikuti program.

Tabel 7.

Keterangan Penghasilan Informan

\begin{tabular}{|c|c|c|}
\hline Informan & Keterangan & $\operatorname{Jumlah}(\mathrm{Rp})$ \\
\hline Informan 4 & Meningkat & Rpl 1680000 \\
\hline Informan 5 & Meningkat & Rpl1290000 \\
\hline Informan 6 & Meningkat & Rpl248000 \\
\hline Informan 7 & Meningkat & Rpl1345000 \\
\hline Informan 8 & Meningkat & Rpl1120000 \\
\hline Informan 9 & Meningkat & Rpp1475000 \\
\hline Informan 10 & Meningkat & Rpl270000 \\
\hline
\end{tabular}

Tabel di atas menunjukkan adanya peningkatan penghasilan informan. Peningkatan penghasilan tersebut merupakan hasil keuntungan yang didapatkan selama mengikuti program.

\section{Bekerja}

Bekerja merupakan salah satu indikator keberhasilan program pemberdayaan. Tabel berikut menunjukkan status bekerja atau tidaknya para informan sebelum dan sesudah program.

\section{Tabel 8.}

Status Bekerja Informan Sebelum dan Sesudah Program

Status Bekerja Informan Sebelum dan Sesudah Program

\begin{tabular}{|l|l|l|}
\hline \multicolumn{1}{|c|}{ Informan } & \multicolumn{1}{|c|}{ Sebelum } & \multicolumn{1}{c|}{ Sesudah } \\
\hline Informan 4 & Bekerja & Bekerja \\
\hline Informan 5 & Bekerja & Bekerja \\
\hline Informan 6 & Bekerja & Bekerja \\
\hline Informan 7 & Tidak Bekerja & Bekerja \\
\hline Informan 8 & Bekerja & Bekerja \\
\hline Informan 9 & Tidak bekeria & Bekerja \\
\hline Informan 10 & Bekerja & Bekerja \\
\hline
\end{tabular}

Tabel tersebut menunjukkan bahwa semua informan sesudah ataupun sebelum mengikuti program, telah bekerja kecuali informan keenam. Informan keenam sebelumnya merupakan Iulusan Sekolah Menengah Atas yang belum mendapatkan pekerjaan. Adanya program ini membuat informan keenam mendapatkan pekerjaan.

\section{Transformasi Mustahik Menjadi Muzakki}

Apabila para mustahik sudah menjadi muzaki, maka zakat yang merupakan dana program pemberdayaan tersebut telah berhasil mentransformasi mustahik menjadi muzaki melalui program pemberdayaan. Hal tersebut merupakan hasil akhir dari 
Sholikhah, et al/Jurnal Ekonomi Syariah Teori dan Terapan Vol. 6 No. 5 Mei 2019: 942-956; PERAN NILAI NILAI UKHUWAH DALAM PEMBERDAYAAN EKONOMI PETERNAK PADA PROGRAM TERNAK DESA BERDAYA NURUL HAYAT DI DESA SIDOMUKTI KECAMATAN KEPOH BARU KABUPATEN BOJONEGORO

program pemberdayaan. Para informan menjelaskan bahwa sebelum dan sesudah program pemberdayaan mereka telah berzakat. Zakat yang mereka keluarkan adalah zakat fitra. Untuk zakat maal mereka belum mampu melakukannya.

Selain program ini belum lama berlangsung, tambahan penghasilan para peternak pun belum bisa dikatakan besar. Maka dari itu program ini dirasa belum mampu mentransformasi mustahik menjadi muzaki. Hal tersebut bukan berarti bahwa program ini gagal, namun masih berproses menuju ke tingkat keberhasilan yang lebih tinggi.

\section{SIMPULAN DAN SARAN}

Berdasarkan hasil analisis dan pembahasan pada bab sebelumnya, maka dapat disimpulkan sebagai berikut:

1. Program ternak berdaya pada Yayasan Nurul Hayat memiliki dampak dalam meningkatkan kesejahteraan peternak Desa Sidomukti, Kecamatan Kepoh Baru, Bojonegoro .

2. Jaringan: Meningkatnya jaringan pertemanan antar informan dan berdifat universal atau tidak membeda-bedakan menyebabkan adanya pertukaran informasi dan hubungan timbal balik positif berupa meningkatnya kesejahteraan informan penerima bantuan pinjaman.

3. Norma: Kesepakatan yang diikuti dan ditaati dengan baik oleh kedua belah pihak menimbulkan rasa keadilan dan tidak adanya perselisihan serta membuat informan mendapatkan motivasi untuk terus mengembangkan usahanya. Bantuan nyata oleh yayasan serta peran aktif peternak dalam menggali potensi yang ada serta menghadapi hambatan yang ada sangat membantu peternak untuk meningkatkan daya saing mereka dan berimbas pada peningkatan pendapatan dan kesejahteraan mereka.

4. Kepercayaan: Pihak yayasan berhuznuzhan bahwa penerima bantuan adalah orang yang amanah dan berkompeten dalam mengembangkan program tersebut guna tercapainya tujuan utama dari program tersebut. Dari ketiga aspek modal sosial yang ada, terlihat bahwa selain jaringan, norma, dan kepercayaan, muncul adanya hubungan timbal balik dan pertukaran informasi pada aspek jaringan dan timbulnya harapan-harapan bagi pihak yayasan dan penerima bantuan.

\section{Saran}

Adapun saran yang dapat penulis sampaikan pada penelitian ini adalah:

1. Bagi masyarakat atau lembaga yayasan agar senantiasa meningkatkan kualitas program tersebut seperti menambah jaringan pertemanan, mematuhi peraturan yang telah ada, dan meningkatkan kepercayaan terhadap kelompok masyarakat untuk tercapainya 
Sholikhah, et al/Jurnal Ekonomi Syariah Teori dan Terapan Vol. 6 No. 5 Mei 2019: 942-956; PERAN NILAI NILAI UKHUWAH DALAM PEMBERDAYAAN EKONOMI PETERNAK PADA PROGRAM TERNAK DESA BERDAYA NURUL HAYAT DI DESA SIDOMUKTI KECAMATAN KEPOH BARU KABUPATEN BOJONEGORO

kehidupan yang baik, selaras, dan maju.

2. Bagi penelitian selanjutnya dapat menjadikan kekurangan pada penelitian ini sebagai pembelajaran dalam penulisan penelitian selanjutnya.

\section{DAFTAR PUSTAKA}

Adi,Isbandi, Rukminto. 2008. Intervensi Komunitas Pengembangan Masyarakat Sebagai Upaya Pemberdayaan Masyarakat. Jakarta:PT. Raja Grafindo Persada.

BPS. Survei Penduduk Miskin. Dipetik 4 4, 2018,http:www.bps.go.id/linkTabelS tatis/view/id/946:www.bps.go.id/lin kTablestatis/view.id.946.

Departemen Agama Rl, 2002. Al-Qur'an Terjemahan Indonesia. Jakarta: PT Sari Agung.

Fauroni, Lukman. 2016. Model Bisnis Berbasis Ukhuwah (studi entitas bisnis pesantren Al-Itiffaq kabupaten Bandung). Skripsi IAIN. Surakarta

Firdaus. 2006. Seratus Cerita Tentang Akhlak: Mahabah dan Ukhuwah. Jakarta: Republika.

Hadi, Agus Purbathin. 2004. Konsep Pemberdayaan, Partisipasi dan KelembagaandalamPembanguna n.

Hikmat, Harry.2010. Strategi Pemberdayaan Masyarakat. Bandung: Humaniora Utama Press. Sanrego, Yulizar D, dan Moch. Taufiq. 2016. Fiqih Tamkin (Fikih
Pemberdayaan). Jakarta : Qisthi Press

Shihab, M. Quraish. 1996. Wawasan AlQur'an, Bandung : Mizan.

Syahra, Rusydi. 2003. Modal Sosial: Konsep dan Aplikasi. Jurnal Masyarakat dan Budaya, Vol. 5, No. 1: 1-20.

Undang-undang Dasar Negara Republik Indonesia Tahun 1945.

Yin, Robert K. 2009. Case Study Reasearch Design and Methods. Fourth Edition. California: Sage Inc. 2012. Studi Kasus: Desain dan Metode. Jakarta: PT Raja Grafindo Persada. 